www.nature.com/pj

\title{
Effect of stirring rate on particle formation in emulsifier-free, organotellurium-mediated living radical emulsion polymerization (emulsion TERP) of styrene
}

\author{
Hirotaka Moribe, Yukiya Kitayama, Toyoko Suzuki and Masayoshi Okubo
}

Particle formation during the initial stages of emulsifier-free organotellurium-mediated living radical emulsion polymerization (emulsion TERP) of styrene at $60^{\circ} \mathrm{C}$ was investigated at two stirring rates (220 and 1000 r.p.m.), in which the styrene phase floated as a layer on an aqueous phase at 220 r.p.m. or became dispersed as droplets at 1000 r.p.m. A water-soluble TERP agent, poly(methacrylic acid) (PMAA)-methyltellanyl (PMAA 30 -TeMe) and a water-soluble thermal initiator, 4,4'-azobis(4-cyanovaleric acid), at alkaline pH were used. The control/livingness was better at 1000 r.p.m. than at 220 r.p.m., and the particle size distribution was also affected by the stirring rate: both nanometer-sized and submicrometer-sized particles were observed at 220 r.p.m., and mainly nanometer-sized particles were observed at 1000 r.p.m. Because the percentage of $\mathrm{PMAA}_{30}-\mathrm{TeMe}$ consumed in the initial stage was much higher at 1000 r.p.m. than at 220 r.p.m., self-assembly nucleation preferentially occurred at 1000 r.p.m., resulting in nanometer-sized particles and good control/livingness. Stirring at 1000 r.p.m. only in the initial stage of the emulsion TERP followed by 220 r.p.m. induced good control/livingness and the formation of mainly nanometer-sized particles. It is concluded that a high stirring rate in the initial stage is important for the emulsion TERP of styrene to obtain good control/ livingness and to control the particle formation mechanism.

Polymer Journal (2012) 44, 205-210; doi:10.1038/pj.2011.115; published online 30 November 2011

Keywords: controlled/living radical polymerization; emulsion polymerization; particle; organotellurium-mediated living radical polymerization (TERP); self-assembly; stirring; styrene

\section{INTRODUCTION}

Recently, organotellurium-mediated living radical polymerization $(\mathrm{TERP})^{1-3}$ has been proposed and developed by Yamago and coworkers. as a novel controlled/living radical polymerization (CLRP) technique. TERP includes thermal dissociation and degenerative chain transfer (DT) as control mechanisms, in which the main control mechanism is DT, and has a sufficiently high chain transfer constant $\left(\mathrm{C}_{\mathrm{ex}}\right)$, which is important for good control/livingness in DT. In a reversible addition-fragmentation chain transfer polymerization, which is a well-known CLRP based on the same DT mechanism, an intermediate radical was formed, ${ }^{4-6}$ resulting in fewer choices of macroinitiators for the preparation of block copolymers. Because organotellurium compounds operating as control agents in TERP do not form the intermediate radical and types of monomers such as methacrylate, acrylate, styrene, acrylamides, and even non-conjugated monomers can be polymerized by TERP, TERP has a high potential for the precision synthesis of functional polymers. TERP has been studied mainly in homogeneous systems such as bulk and solution polymerizations since $2002 .^{3,7-10}$
In recent years, CLRP in aqueous heterogeneous systems, such as miniemulsion polymerization, microemulsion polymerization and emulsion polymerization, has attracted a great deal of attention because the media is non-toxic and environmentally friendly. ${ }^{11,12}$ Because the control agents used for CLRP thus far have typically been hydrophobic, most of the research efforts in this area have studied miniemulsion polymerization, which ideally proceeds in hydrophobic monomer droplets. ${ }^{13-17}$ There has been great interest in the possibility of applying CLRP to emulsion polymerization, but it has been difficult to realize because of problems with the transfer of the control agent. Specifically, the main problem is that the hydrophobic control agent in a monomer droplet does not transfer smoothly into micelles (particles) as polymerization loci via an aqueous medium. As a result, the hydrophobic control agent is mainly partitioned in monomer droplets. ${ }^{18-20}$ As a solution of the problem, Hawkett and coworkers recently proposed an emulsifier-free reversible addition-fragmentation chain transfer emulsion polymerization method utilizing self-assembly. ${ }^{21,22}$ Following this proposal, nitroxide-mediated radical polymerization ${ }^{23-28}$ and reversible addition- 
fragmentation chain transfer ${ }^{29-35}$ in emulsion polymerization systems have been successfully studied.

In previous works utilizing the self-assembly approach, we applied TERPs of $n$-butyl acrylate and styrene to a batch emulsifier-free emulsion polymerization (emulsion TERP) using a highly hydrophilic TERP agent, poly(methacrylic acid) (PMAA; degree of polymerization, 30) and methyltellanyl (PMAA 30 -TeMe). ${ }^{36-40}$ Emulsion TERPs of $n$-butyl acrylate and styrene proceeded with high livingness, and the molecular weights of obtained polymers could be adequately controlled. Interestingly, the stirring rate significantly affected the polymerization rate $\left(R_{\mathrm{p}}\right)$ and molecular weight distribution (MWD) in both systems. These phenomena were discussed from a viewpoint of monomer transfer from monomer droplets to polymerizing particles. ${ }^{40}$ Additionally, the particle size distribution was also found to be strongly dependent on the stirring rate. However, the mechanism for this size distribution dependence at different stirring rates was not obvious.

In this work, emulsion TERPs of styrene were carried out at two stirring rates to clarify the effect of stirring rate on particle formation. The MWD in the initial stage of the polymerization will be especially investigated in detail because the initial stage is very important for understanding the mechanism of particle formation in a general emulsion polymerization.

\section{EXPERIMENTAL PROCEDURE}

\section{Materials}

Styrene (Nacalai Tesque, Kyoto, Japan) was purified by distillation under reduced pressure in a nitrogen atmosphere. The deionized water used in all the experiments was obtained using an Elix UV (Millipore, Tokyo, Japan) purification system that had a resistivity of $18.2 \mathrm{M} \Omega \mathrm{cm}^{-1} .4,4^{\prime}$-Azobis(4cyanovaleric acid) (V-501, Wako Pure Chemicals, Osaka, Japan) was purified by recrystallization in water. $\mathrm{PMAA}_{30}$-TeMe (ratio of weight-average molecular weight $\left(M_{\mathrm{w}}\right)$ to number-average molecular weight $\left.\left(M_{\mathrm{n}}\right)\left(M_{\mathrm{w}} / M_{\mathrm{n}}\right) \sim 1.1\right)$ was supplied from Otsuka Chemical Co., Ltd., Osaka, Japan, and trimethylsilyldiazomethane (Nacalai Tesque) was used as received.

\section{Emulsion TERP of styrene}

A typical procedure is described below. First, water and styrene were separately deoxygenized by nitrogen bubbling. Subsequently, V-501 (10.5 mg, $37.8 \mu \mathrm{mol})$ and a $\mathrm{NaOH}$ aqueous solution $\left(45 \mathrm{~g}, 1.68 \times 10^{-3} \mathrm{M}\right.$, equivalent to carboxyl groups of V-501) were added to a round-bottom Schlenk flask, which was sealed off with a silicon rubber septum and then degassed using several $\mathrm{N}_{2}$ / vacuum cycles. $\mathrm{PMAA}_{30}$-TeMe $(295 \mu \mathrm{l}, 0.127 \mathrm{M}$ aqueous solution neutralized by $\mathrm{NaOH}(\mathrm{pH}=13), 37.8 \mu \mathrm{mol})$ was injected into the system using a syringe. After styrene $(1.57 \mathrm{~g}, 15 \mathrm{mmol})$ had been injected and the mixture was degassed again using several vacuum $/ \mathrm{N}_{2}$ cycles, the flask was then placed in a water bath at $60^{\circ} \mathrm{C}$ (considered as the start of the polymerization, $t=0$ ). The polymerization was allowed to proceed for a given time at one of two stirring rates of 220 or 1000 r.p.m. using a magnetic stirrer.

\section{Characterization}

Conversion was measured by gravimetry. The number-average molecular weight $\left(M_{\mathrm{n}}\right)$ and MWD were measured by gel permeation chromatography using two styrene/divinylbenzene gel columns (TOSOH Corp., Tokyo, Japan; TSKgel $\mathrm{GMH}_{\mathrm{HR}}-\mathrm{H}, 7.8 \mathrm{~mm}$ i.d. (inside diameter) $\times 30 \mathrm{~cm}$ ) using $\mathrm{THF}$ as an eluent at $40^{\circ} \mathrm{C}$ at a flow rate of $1.0 \mathrm{ml} \mathrm{min}^{-1}$ employing refractive index (TOSOH RI$8020 / 21$ ) and ultraviolet detectors (TOYO SODA UV-8II). The columns were calibrated with six standard polystyrene (PS) samples $\left(1.05 \times 10^{3}-5.48 \times 10^{6}, M_{\mathrm{w}} /\right.$ $\left.M_{\mathrm{n}}=1.01-1.15\right)$. Before gel permeation chromatography measurement, $\mathrm{PMAA}_{30}$-TeMe and $\mathrm{PMAA}_{30}-b$-PS-TeMe were modified by methylating the carboxyl group using trimethylsilyldiazomethane as follows. After acidification of the carboxyl group, each polymer was recovered by drying the polymer emulsion. The polymer was dissolved in a mixture of dimethylformamide and methanol at room temperature. A yellow solution of trimethylsilyldiazomethane was added at room temperature into the polymer solution, and the reaction was allowed to continue overnight. After the excess trimethylsilyldiazomethane was neutralized by acetic acid, poly(methyl methacrylate)(PMMA) 30 -TeMe and $\mathrm{PMMA}_{30}-b$-PS-TeMe solutions were diluted with a large amount of THF and used for gel permeation chromatography measurements. The theoretical molecular weight $\left(M_{\mathrm{n}, \mathrm{th}}\right)$ was calculated using the following equation:

$$
M_{n, t h}=\mathrm{MW}_{\mathrm{PMAA}_{30}-\mathrm{TeMe}}+\left(\frac{[\mathrm{M}]_{0} \cdot \mathrm{MW}_{\mathrm{M}} \cdot \alpha}{[\mathrm{PMAA}-\mathrm{TeMe}]_{0}}\right)
$$

where $\alpha$ is the conversion fraction of monomer, $\mathrm{MW}_{\mathrm{PMAA} 30-\mathrm{TeMe}}$ and $\mathrm{MW}_{\mathrm{M}}$ are the molecular weights of $\mathrm{PMAA}_{30}-\mathrm{TeMe}$ and styrene, respectively, and $\left[\mathrm{PMAA}_{30}-\mathrm{TeMe}\right]_{0}$ and $[\mathrm{M}]_{0}$ are the initial concentrations of $\mathrm{PMAA}_{30}-\mathrm{TeMe}$ and the monomer, respectively. In the above equation, the contribution of polymer chains derived from V-501 to $M_{\mathrm{n}, \mathrm{th}}$ was neglected because the number of the polymer chains was small compared with that of polymer chains derived from $\mathrm{PMAA}_{30}$-TeMe. The consumption of $\mathrm{PMAA}_{30}$-TeMe was estimated by transforming the MWDs to the number distributions, $\left(w(\log M) / M^{2}\right)$ vs $M$. The weight distributions, $(w(\log M) / M)$ vs $M$, were normalized with respect to each conversion before the transformation. The number of chains could be calculated as the integral of the number distributions; therefore, the number of remaining $\mathrm{PMAA}_{30}$-TeMe could also be obtained.

The particle size distribution and number-average particle diameter $\left(d_{\mathrm{n}}\right)$ were measured using transmission electron microscopy (TEM) (JEOL, Tokyo, Japan, JEOL JEM-1230) and dynamic light scattering (DLS, FPAR-1000 RK, fiber-optics particle analyzer, Photal Otsuka Electronics, Osaka, Japan). TEM samples were prepared by diluting each emulsion to $\sim 50 \mathrm{ppm}$ with water and then placing a drop of this solution on a carbon-coated copper grid and drying at room temperature in a desiccator. In the DLS measurement, 1-2 droplets of emulsion samples withdrawn from the reactor were diluted with $\sim 8 \mathrm{ml}$ of distilled water before measurements using the dilution mode at a perpendicular light scattering angle at $25^{\circ} \mathrm{C}$ using the Contin analysis routine.

\section{RESULTS AND DISCUSSION}

Emulsion TERP of styrene was carried out at $60^{\circ} \mathrm{C}$ with stirring at 220 or 1000 r.p.m. as previously reported. ${ }^{40}$ The stirring rate greatly affected the dispersed state of styrene. At 220 r.p.m., most of the styrene floated as an upper layer, whereas a large number of styrene droplets were dispersed in the aqueous phase at 1000 r.p.m. As shown in Figure 1, both polymerizations proceeded smoothly, and the polymerizations were almost complete by $30 \mathrm{~h}$ without any coagulation. Table 1 shows

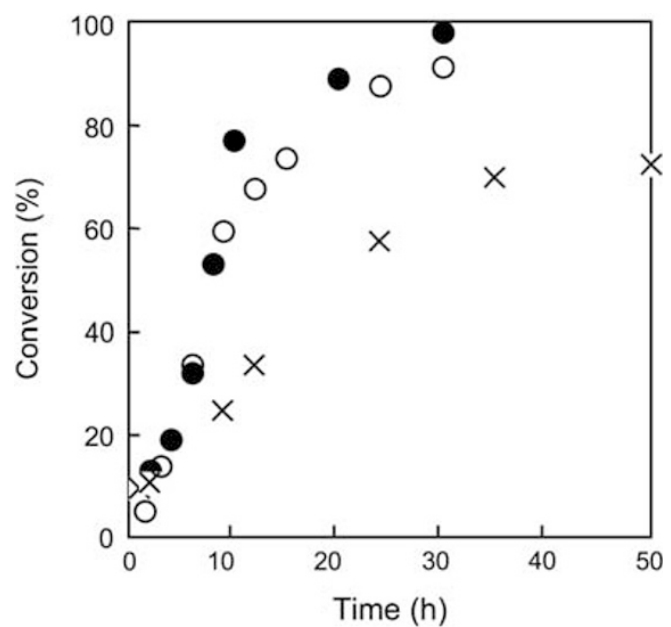

Figure 1 Conversion vs time plots for the emulsion TERP using poly(methacrylic acid)-methyltellanyl (PMAA 30 -TeMe) and $\mathrm{V}-501$ at $60^{\circ} \mathrm{C}$ with constant stirring at 220 r.p.m. (open circle), constant 1000 r.p.m. (closed circle) or 1000 r.p.m. for $2 \mathrm{~h}$ followed by 220 r.p.m. (cross symbol). Styrene/PMAA $30-T e M e / V-501$ (molar ratio)=400/1/1. 
the characteristics of the PS obtained by the emulsion TERP preparation method. At 1000 r.p.m., the experimental $M_{\mathrm{n}}$ was much closer to $M_{\mathrm{n}, \mathrm{th}}$, and the $M_{\mathrm{w}} / M_{\mathrm{n}}$ value was lower than the corresponding values observed for samples stirred at 220 r.p.m. These results indicate that 1000 r.p.m. stirring resulted in much better control than 220 r.p.m. In our previous work, we observed that the early disappearance of the monomer phase and the high monomer concentration inside the polymerizing particles $\left([\mathrm{M}]_{\mathrm{p}}\right)$, which were greatly affected by stirring rate, were important factors for obtaining good control in emulsion TERP. ${ }^{40}$

Figure 2 shows TEM images of PS particles at various conversions prepared by emulsion TERP at $60^{\circ} \mathrm{C}$ with stirring at 220 and 1000 r.p.m. At 220 r.p.m., in addition to nanometer-sized particles, submicrometer-sized particles were obtained from the initial stage of the polymerization. However, nanometer-sized particles were obtained mainly at 1000 r.p.m. throughout the polymerization.

The polymer particles would be formed by two mechanisms in the emulsion TERP using $\mathrm{PMAA}_{30}$-TeMe and $\mathrm{V}-501 .^{38}$ One is 'selfassembly nucleation,' in which amphiphilic block copolymers are formed in an aqueous phase at the initial stage of the polymerization self-assembly, resulting in 'micelles' that solubilize the monomer within. The micelles, which act like low-molecular-weight emulsifier

Table 1 Characteristics of PS prepared by the emulsion TERP in $30 \mathrm{~h}$ at $60^{\circ} \mathrm{C}$ with stirring at 220,1000 or 1000 r.p.m. followed by 220 r.p.m.

\begin{tabular}{lcccc}
\hline Stirring rate (r.p.m.) & Conversion (\%) & $\mathrm{M}_{n, \text { th }}$ & $\mathrm{M}_{n}$ & $\mathrm{M}_{w} / \mathrm{M}_{n}$ \\
\hline 220 & 98 & $4.4 \times 10^{4}$ & $1.1 \times 10^{5}$ & 2.8 \\
1000 & 90 & $4.1 \times 10^{4}$ & $4.9 \times 10^{4}$ & 1.3 \\
$1000 \rightarrow 220$ & 81 & $3.9 \times 10^{4}$ & $5.5 \times 10^{4}$ & 1.4
\end{tabular}

Abbreviation: $M_{n}$, number-average molecular weight; $M_{n, t h}$, theoretical molecular weight $M_{w}$, weight-average molecular weight; PS, polystyrene.

Styrene/poly(methacrylic acid)-methyltellanyl/N-501 (molar ratio)=400/1/1 'micelles' in a conventional emulsion polymerization, work as polymerization loci, resulting in stable nanometer-sized PS particles because of an ionized 'hairy' surface layer comprising the sodium PMAA $_{30}$ block. The other mechanism is 'homogeneous nucleation,' which also occurred in emulsifier-free emulsion polymerization. ${ }^{41}$ In this process, ionized initiator radicals derived from $\mathrm{V}-501$ in the presence of a $\mathrm{pH}>8$ react with monomers dissolving in the aqueous phase up to a certain critical degree of polymerization $\left(J_{\text {crit }}\right)$ and form oligomers that precipitate in the aqueous phase when $J_{\text {crit }}$ is reached for a given chain, eventually resulting in the formation of primary particles. Because the primary particles are not sufficiently stable, they aggregate with each other, resulting in submicrometer-sized particles. At $96 \%$ conversion, the $M_{\mathrm{n}}$ of PS in the nanometer-sized particles was relatively close to $M_{\mathrm{n}, \mathrm{th}}$, whereas that in the submicrometer-sized particles was much higher than $M_{\mathrm{n}, \mathrm{th}} \cdot{ }^{37}$ The ratio $M_{\mathrm{w}} / M_{\mathrm{n}}$ was lower in the nanometer-sized particles $(\sim 2.4)$ than in the submicrometer-sized particles $(\sim 2.6)$, although both values were rather high in comparison with a general CLRP. These results indicate that the particle formation in the initial stage significantly affects control/livingness in emulsion TERP. In the previous work, it was revealed that the particle size distribution in the emulsion TERP was fixed in the initial stage of the polymerization. ${ }^{38}$ In this study, because a similar tendency was observed at both stirring rates (Figure 1), the particle nucleation in the initial stage needs to be discussed in detail.

Figures $3 \mathrm{a}$ and $\mathrm{b}$ show the MWDs (refractive index detector) of PS in the initial stage of the emulsion TERP at $60^{\circ} \mathrm{C}$ with stirring at 220 or 1000 r.p.m., respectively. The MWDs of the obtained polymers were bimodal in the initial stage of the emulsion TERP because of the presence of two polymerization loci (aqueous phase and polymerizing particles), and the peak at low molecular weight $(\log M=3.5)$ was due to the unconsumed control agent (original $\mathrm{PMAA}_{30}$-TeMe) and $\mathrm{PMAA}_{30}-b$-PS-TeMe, (which still does not form micelles) in the aqueous phase. ${ }^{39}$ The fraction of consumed $\mathrm{PMAA}_{30}$-TeMe in the initial stage of the polymerization was calculated in both stirring rates
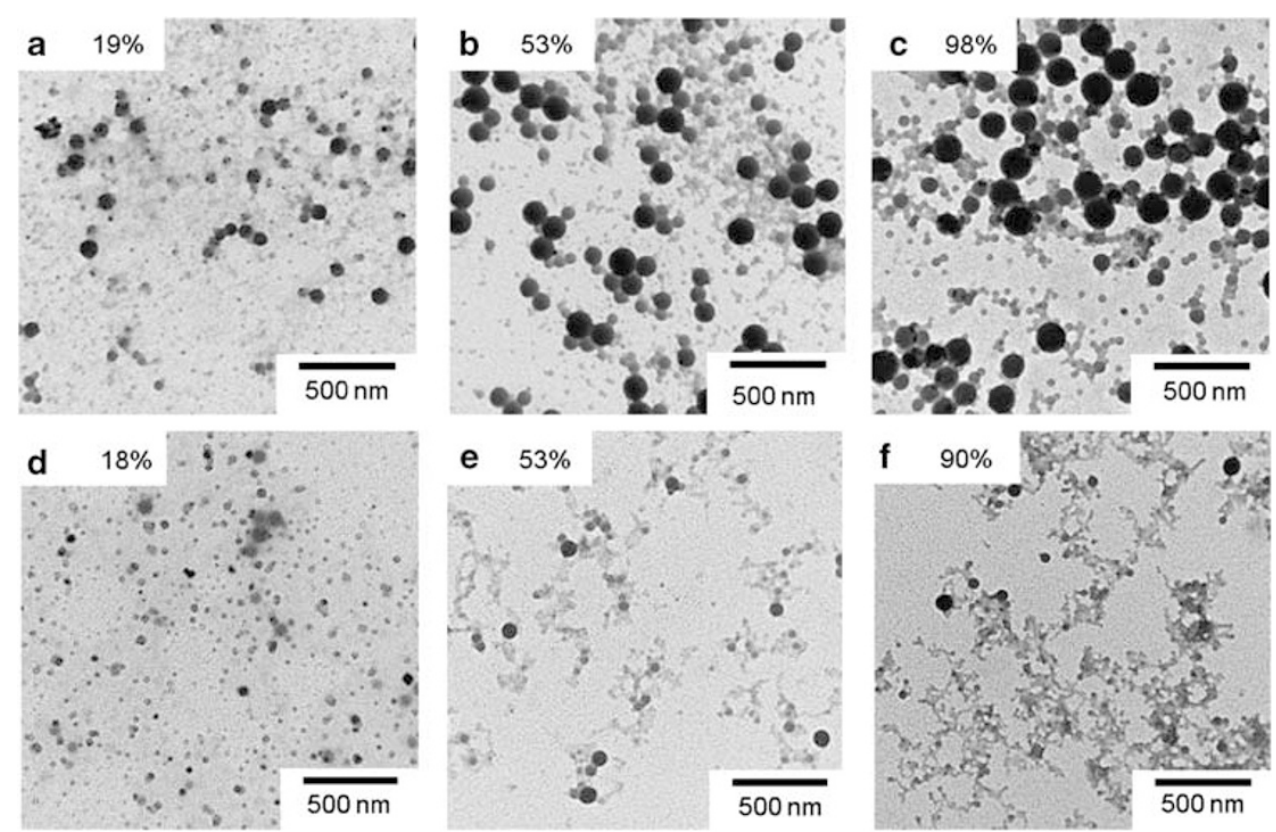

Figure 2 Transmission electron microscopy photographs of polystyrene particles at different conversions of the emulsion TERP using poly(methacrylic acid)methyltellanyl (PMAA $30-\mathrm{TeMe}$ ) and V-501 at $60^{\circ} \mathrm{C}$ with stirring at 220 r.p.m. (a-c) or 1000 r.p.m. (d-f). Conversions (\%): (a) 19; (b) 53; (c) 98; (d) 18; (e) 53; (f) 90. Styrene/PMAA $30-\mathrm{TeMe} / \mathrm{V}-501$ (molar ratio) $=400 / 1 / 1$. 

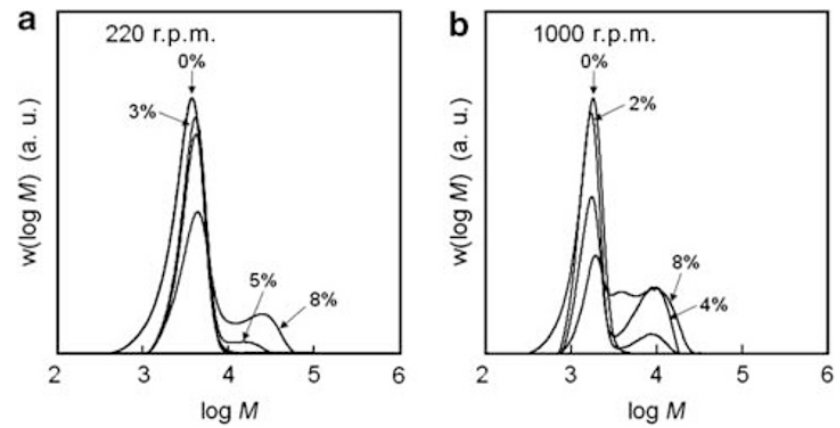

Figure 3 MWD (refractive index detector) of $\mathrm{PMAA}_{30}-b$-PS-TeMe (after methylation) at different conversions of the emulsion TERP using poly(methacrylic acid)-methyltellanyl ( $\mathrm{PMAA}_{30}-\mathrm{TeMe}$ ) and $\mathrm{V}-501$ at $60^{\circ} \mathrm{C}$ with stirring at 220 r.p.m. (a) or 1000 r.p.m. (b). Styrene/PMAA ${ }_{30}-\mathrm{TeMe} /$ V-501 (molar ratio) $=400 / 1 / 1$.

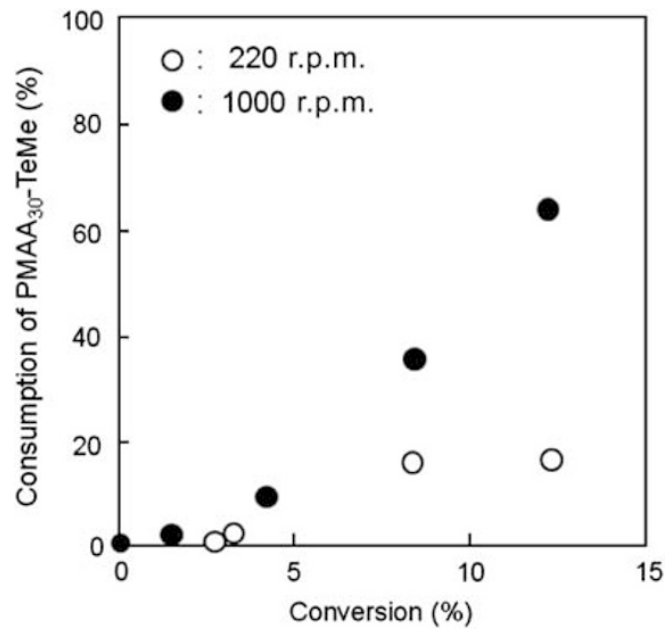

Figure 4 Consumption of poly(methacrylic acid)-methyltellanyl $\left(\mathrm{PMAA}_{30-}\right.$ $\mathrm{TeMe}$ ) at different conversions of the emulsion TERP using $\mathrm{PMAA}_{30}$-TeMe and V-501 at $60^{\circ} \mathrm{C}$ with stirring at 220 (open circles) or 1000 r.p.m. (closed circles). Styrene/PMAA $30-\mathrm{TeMe} / \mathrm{V}-501$ (molar ratio)=400/1/1.

using the MWDs (Figure 4) following the same procedure described in the previous article. ${ }^{40}$ At 1000 r.p.m., the fraction of the consumed $\mathrm{PMAA}_{30}$-TeMe was higher than that at 220 r.p.m. This result indicates that at 1000 r.p.m., because the formation of amphiphilic $\mathrm{PMAA}_{30^{-}} b$ PS-TeMe was rapid and a correspondingly larger number of particles would be formed by self-assembly nucleation, a nanometer-sized monomodal particle size distribution will be observed (Figures $2 \mathrm{~d}-\mathrm{f}$ ).

In a previous work, we found that styrene concentrations in micelles $\left([\mathrm{M}]_{\mathrm{m}}\right)$ comprising of polyoxyethylene nonylphenyl ether with an average of 10.9 ethylene oxide per molecule (Emulgen 911, Kao, Co., Tokyo, Japan) as a non-ionic emulsifier after $100 \mathrm{~min}$ stirring at 240 or 500 r.p.m. at $70^{\circ} \mathrm{C}$ in aqueous media were 5.6 and $8.7 \mathrm{moll}^{-1}$ styrene-swollen micelles, respectively. ${ }^{42}$ The calculated $[\mathrm{M}]_{\mathrm{m}}$ values were primarily found using data on the diameter of the micelles and the amount of monomer in the micelles, which were measured by DLS and gas chromatography, respectively. These results indicate that the dissolution rate of styrene in water became faster as the stirring rate increased.

The difference in the consumption of $\mathrm{PMAA}_{30}-\mathrm{TeMe}$ in the initial stage due to the stirring rate (shown in Figure 4) seems to be based on

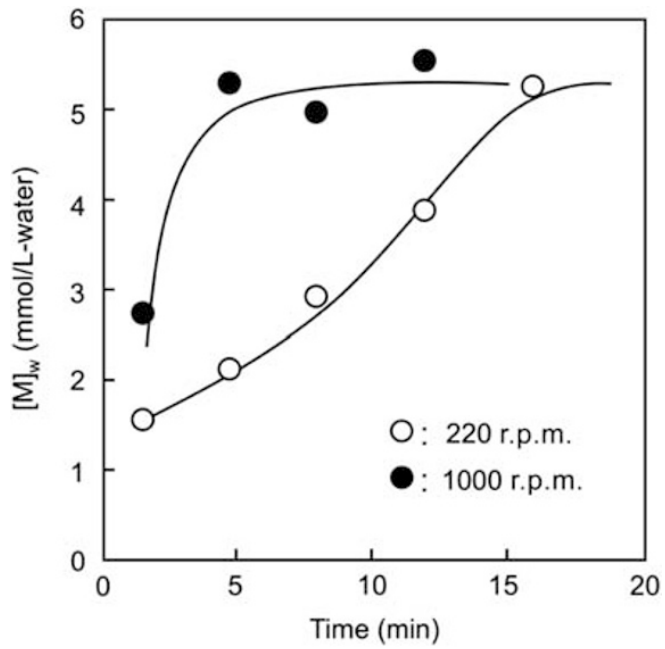

Figure 5 Monomer concentration in water $\left([\mathrm{M}]_{\mathrm{w}}\right)$ vs time plots at $60^{\circ} \mathrm{C}$ with stirring at 220 (open circles) or 1000 r.p.m. (closed circles). Monomer content $=3.4 \mathrm{wt} \%$.

the difference in the diffusion rate of styrene from monomer droplets into the aqueous phase, which leads to the high styrene concentration in the aqueous phase at 1000 r.p.m. stirring.

Figure 5 shows that styrene concentration in water $\left([\mathrm{M}]_{\mathrm{w}}\right)$ vs time plots at $60^{\circ} \mathrm{C}$ with stirring at rates of 220 or 1000 r.p.m. Under the high diffusion rate at 1000 r.p.m., that is, high $[\mathrm{M}]_{\mathrm{W}}$, the addition of styrene to radical species proceeds rapidly in the aqueous phase, resulting in a faster consumption of $\mathrm{PMAA}_{30}$-TeMe in the initial stage. Because the faster consumption of $\mathrm{PMAA}_{30}$-TeMe decreases the time period available for particle nucleation, during the particle nucleation period, the number of initiator radicals generated with an ionized carboxylic end group, which potentially form submicrometer-sized particles, is small. As a result, at 1000 r.p.m. stirring, homogeneous nucleation is negligible, and self-assembly nucleation preferentially occurs.

Based on the ideas described above for the difference of the particle nucleation mechanism due to the stirring rate, it seems that the 1000 r.p.m. stirring should be adopted at least in the initial stage of the polymerization to obtain good control and nanometer-sized particles. To confirm this hypothesis, emulsion TERP of styrene was carried out at $60^{\circ} \mathrm{C}$ with stirring at 1000 r.p.m. for $2 \mathrm{~h}$ until a conversion of $11 \%$ was reached, followed by stirring at 220 r.p.m.

The conversion vs time plot for the emulsion TERP is shown as a cross symbol in Figure 1. The polymerization proceeded smoothly in nanometer-sized particles, but $R_{\mathrm{p}}$ was slower than those with constant stirring at 220 or 1000 r.p.m. We have previously reported that the confined space effect reduced the $R_{\mathrm{p}}$ in nanometer-sized particles in aqueous dispersed nitroxide-mediated radical polymerization and atom transfer radical polymerization systems. ${ }^{43,44}$ Because TERP proceeded under the DT mechanism at $60^{\circ} \mathrm{C}$, the confined space effect should not occur in the system. At the constant stirring rate of 1000 r.p.m., the monomer droplets were dispersed in the aqueous phase, which induced high $[\mathrm{M}]_{\mathrm{p}}$ due to high monomer diffusion from monomer droplets to polymerizing particles compared with the constant 220 r.p.m., in which the monomer phase floated on the aqueous phase. In our previous work, we revealed that the $[M]_{p}$ was much lower at a constant 220 r.p.m. than at a constant 1000 r.p.m. ${ }^{40}$ A decrease in $[\mathrm{M}]_{\mathrm{p}}$ in the emulsion TERP would also result in a decrease in the $R_{\mathrm{p}}$. It is well known that the number of the polymer particles $\left(N_{\mathrm{p}}\right)$ affects the $R_{\mathrm{p}}$ in a general emulsion 

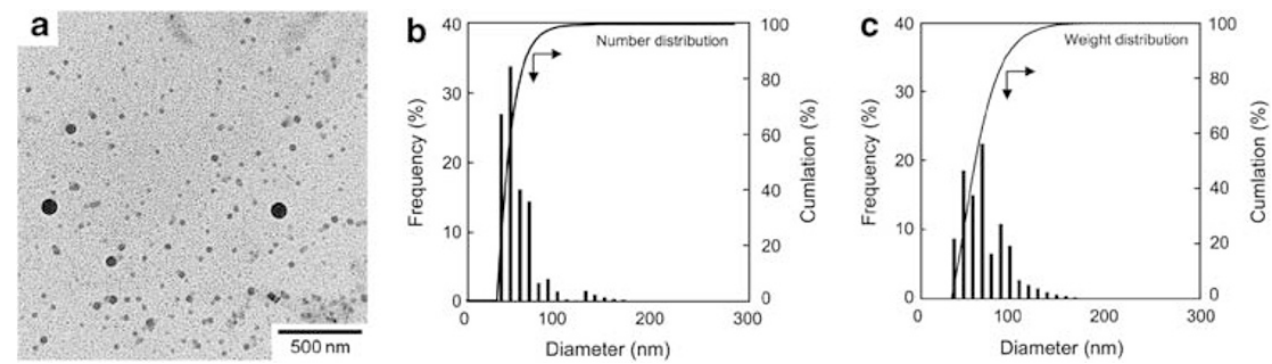

Figure 6 Transmission electron microscopy photograph (a) and particle size distribution (number distribution (b), weight distribution (c)) measured with dynamic light scattering of polystyrene particles prepared by the emulsion TERP using poly(methacrylic acid)-methyltellanyl (PMAA $30-T_{e M e)}$ and V-501 at $60^{\circ} \mathrm{C}$ with stirring at 1000 r.p.m. for $2 \mathrm{~h}$ followed by 220 r.p.m. Styrene/PMAA $30-T e M e / V-501$ (molar ratio)=400/1/1.
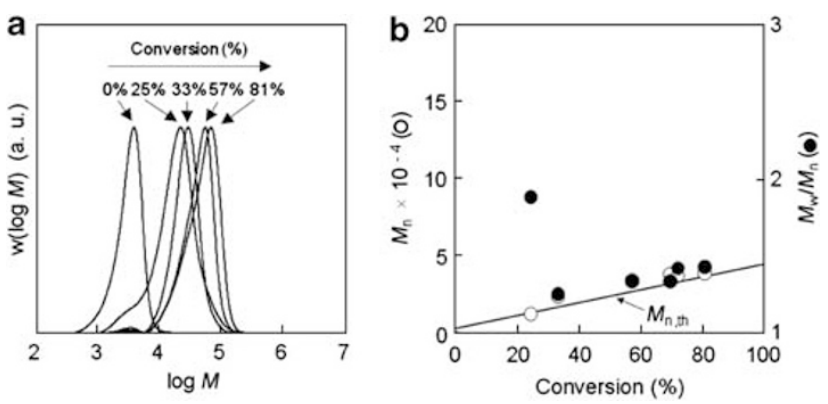

Figure 7 MWD (refractive index detector) (a), $M_{\mathrm{n}}$ (open circles) and $M_{\mathrm{w}} / M_{\mathrm{n}}$ (closed circles) (b) of $\mathrm{PMMA}_{30}$-b-PS-TeMe (after methylation) at different conversions of the emulsion TERP using poly(methacrylic acid)-methyltellanyl $\left(\mathrm{PMAA}_{30}-\mathrm{TeMe}\right.$ ) and $\mathrm{V}-501$ at $60^{\circ} \mathrm{C}$ with stirring at 1000 r.p.m. followed by 220 r.p.m. Styrene/PMAA $30-T e M e / V-501$ (molar ratio)=400/1/1. The line is the theoretical $M_{\mathrm{n}}\left(M_{\mathrm{n}, \mathrm{th}}\right)$.

polymerization. In this study, $N_{\mathrm{p}}$ was larger at the constant 1000 r.p.m. rate than at the constant 220 r.p.m. rate, which results in the lower $R_{\mathrm{p}}$ at the constant 220 r.p.m. However, the $R_{\mathrm{p}}$ was high at a constant 220 r.p.m. as well as at a constant 1000 r.p.m. even though the $[\mathrm{M}]_{\mathrm{p}}$ was low and $N_{\mathrm{p}}$ was small. These results could be explained by the gel effect that occurs in the case of extremely low $[\mathrm{M}]_{\mathrm{p}}$, even in an intermediate polymerization where monomer droplets still exist, which is described as follows. A termination rate constant $\left(k_{\mathrm{t}}\right)$, which is a reaction between polymer radicals, decreases under a diffusion-controlled state at the higher viscosity inside polymerizing particles due to the much lower $[\mathrm{M}]_{\mathrm{p}},{ }^{45,46}$ resulting in an increase in $R_{\mathrm{p}}$ with constant 220 r.p.m. stirring. The influence of these conflicting factors affecting the polymerization happened to cancel offset one another, and as the result, it seems that the $R_{\mathrm{p}}$ at 220 r.p.m. was the similar as that at 1000 r.p.m. Because $[\mathrm{M}]_{\mathrm{p}}$ is high even when the stirring rate was decreased instantly from 1000 to 220 r.p.m. at $11 \%$ conversion, the gel effect does not appear at once in the emulsion TERP. As the result, $R_{\mathrm{p}}$ becomes lower than that determined for the constant 220 r.p.m. stirring rate.

Figure 6 shows TEM images and particle size distributions (number- and weight-distribution) measured with DLS of PS particles at the final conversion prepared by the emulsion TERP at $60^{\circ} \mathrm{C}$ with stirring at 1000 r.p.m. for $2 \mathrm{~h}$, followed by 220 r.p.m. The particle size obtained from DLS was slightly larger than that from the TEM images because the PMAA hairy layer shrank in the TEM images. As expected, the fraction of the submicrometer-sized particles was low, and the particle size distribution was monomodal $\left(D_{\mathrm{n}}=51 \mathrm{~nm}\right)$, similar to those with constant 1000 r.p.m. stirring. Figure 7 shows the MWD, $M_{n}$ and $M_{\mathrm{w}} / M_{\mathrm{n}}$ of PS obtained at different conversions of the emulsion TERP. The MWD shifted to higher molecular weight with increasing conversion, similar to the MWDs observed with constant 220 or 1000 r.p.m. stirring. ${ }^{40}$ The $M_{\mathrm{n}}$ was close to $M_{\mathrm{n} \text {,th }}$ and the $M_{\mathrm{w}} / M_{\mathrm{n}}$ values were sufficiently low $(\sim 1.4)$ except for the initial stage. In addition, only $\sim 16 \%$ of the fraction of unconsumed PMAA $_{30}$-TeMe remained at the final conversion. The value was similar to that with constant stirring at 1000 r.p.m.

From these results, we conclude that the initial stage is important for particle formation in the emulsion TERP of styrene, as well as in general emulsion polymerization and that a high stirring rate is necessary, at least in the initial stage, to induce the formation of nanometer-sized particles based on self-assembly nucleation, which results in good control of $M_{\mathrm{n}}$ and $M_{\mathrm{w}} / M_{\mathrm{n}}$.

\section{CONFLICT OF INTEREST}

The authors declare no conflict of interest.

\section{ACKNOWLEDGEMENTS}

We are grateful to Otsuka Chemical Co., Ltd. for supplying the organotellurium compounds. This work was partially supported by Grant-in-Aid for Scientific Research (A) (Grant 21245050) from the Japan Society for the Promotion of Science (JSPS) and by Research Fellowship of JSPS for Young Scientists (given to YK).

1 Yamago, S., Iida, K. \& Yoshida, J. Organotellurium compounds as novel initiators for controlled/living radical polymerizations. Synthesis of functionalized polystyrenes and end-group modifications. J. Am. Chem. Soc. 124, 2874-2875 (2002).

2 Yamago, S. Development of organotellurium-mediated and organostibinie-mediated living radical polymerization reactions. J. Polym. Sci.; Part A: Polym. Chem. 44, 1-12 (2006).

3 Yamago, S. Precision polymer synthesis by degenerative transfer controlled/living radical polymerization using organotellurium, organostibine, and organobismuthine chain-transfer agents. Chem. Rev. 109, 5051-5068 (2009).

4 Chiefari, J., Chong, Y. K., Ercole, F., Krstina, J., Jeffery, J., Le, T. P. T., Mayadunne, R. T. A., Meijs, G. F., Moad, C. L., Moad, G., Rizzardo, E. \& Thang, S. H. Living free-radical polymerization by reversible addition-fragmenattion chain transfer: the RAFT process. Macromolecules 31, 5559-5562 (1998).

5 Moad, G., Chong, Y. K., Postma, A., Rizzardo, E. \& Thang, S. H. Advances in RAFT polymerization: the synthesis of polymers with defined end-groups. Polymer 46, 8458-8468 (2005).

6 Moad, G., Rizzardo, E. \& Thang, S. H. Living radical polymerization by the RAFT process - a first update. Aust. J. Chem. 59, 669-692 (2006).

7 Goto, A., Kwak, Y., Fukuda, T., Yamago, S., Iida, K., Nakajima, M. \& Yoshida, J. Mechanism-based invention of high-speed living radical polymerization using organotellurium compounds and azo-initiators. J. Am. Chem. Soc. 125, 8720-8721 (2003).

8 Yamago, S., Ray, B., Iida, K., Yoshida, J., Tada, T., Yoshizawa, K., Kwak, Y., Goto, A. \& Fukuda, T. Highly versatile organostibine mediators for living radical polymerization. J. Am. Chem. Soc. 126, 13908-13909 (2004).

9 Kwak, Y., Goto, A., Fukuda, T., Kobayashi, Y. \& Yamago, S. A systematic study on activation processes in organotellurium-mediated living radical polymerizations of 
styrene, methyl methacrylate, methyl acrylate, and vinyl acetate. Macromolecules 39, 4671-4679 (2006).

10 Kwak, Y., Tezuka, M., Goto, A., Fukuda, T. \& Yamago, S. Kinetic study on role of ditelluride in organotellurium-mediated living radical polymerization (TERP). Macromolecules 40, 1881-1885 (2007).

11 Cunningham, M. F. Controlled/living radical polymerization in aqueous dispersed systems. Prog. Polym. Sci. 33, 365-398 (2008).

12 Zetterlund, P. B., Kagawa, K. \& Okubo, M. Controlled/living radical polymerization in dispersed systems. Chem. Rev. 108, 3747-3794 (2008).

13 Sugihara, Y., Kagawa, Y., Yamago, S. \& Okubo, M. Organotellurium-mediated living radical polymerizaiton in miniemulsion. Macromolecules 40, 9208-9211 (2007).

14 Pan, G., Sudol, E. D., Dimonie, V. L. \& El-Aasser, M. S. Nitroxide-mediated living free radical miniemulsion polymerization of styrene. Macromolecules $34,481-488$ (2001).

15 Zetterlund, P. B., Alam, M. N., Minami, H. \& Okubo, M. Nitroxide-mediated controlled/ living free radical copolymerization of $\mathrm{S}$ and DVB in aqueous miniemulsion. Macromol. Rapid Commun. 26, 955-960 (2005).

16 Cunningham, M. F. Living/controlled radical polymerizations in dispersed phase systems. Prog. Polym. Sci. 27, 1039-1067 (2002).

17 Qiu, J., Charleux, B. \& Matyjaszewski, K. Controlled/living radical polymerization in aqueous media: homogeneous and heterogeneous systems. Prog. Polym. Sci. 26 , 2083-2134 (2001).

18 Monteiro, M. J. \& de-Barbeyrac, J. Free-radical polymerization of styrene in emulsion using a reversible addition-fragmentation chain transfer agent with a low transfer constant: effect on rate, particle size, and molecular weight. Macromolecules 34, 4416-4423 (2001).

19 Prescott, S. W., Ballard, M. J., Rizzardo, E. \& Gilbert, R. G. Successful Use of RAFT techniques in seeded emulsion polymerization of styrene: living character, RAFT agent transport, and rate of polymerization. Macromolecules 35, 5417-5425 (2002).

20 Prescott, S. W., Ballard, M. J., Rizzardo, E. \& Gilbert, R. G. RAFT in emulsion polymerization: what makes it different? Aust. J. Chem. 55, 415-424 (2002).

21 Ferguson, C. J., Hughes, R. J., Pham, B. T. T., Hawkett, B. S., Gilbert, R. G., Serelis, A. K. \& Such, C. H. Effective Ab Initio Emulsion Polymerization under RAFT Control. Macromolecules 35, 9243-9245 (2002).

22 Ferguson, C. J., Hughes, R. J., Nguyen, D., Pham, B. T. T., Gilbert, R. G., Serelis, A. K., Such, C. H. \& Hawkett, B. S. Ab-Initio emulsion polymerizaiton by RAFT-controlled self-assemblingly. Macromolecules 38, 2191 (2005).

23 Nicolas, J., Charleux, B., Guerret, O. \& Magnet, S. Nitroxide-mediated controlled freeradical emulsion polymerization of styrene and $\mathrm{nBA}$ with a water-soluble alkoxyamine as initiator. Angew. Chem. Int. Ed. 43, 6186-6189 (2004).

24 Nicolas, J., Charleux, B., Guerret, O. \& Magnet, S. Nitroxide-mediated controlled freeradical emulsion polymerization using a difunctional water-soluble alkoxyamine initiator. Toward the control of particle size, particle size distribution, and the synthesis of triblock copolymers. Macromolecules 38, 9963-9973 (2005).

25 Nicolas, J., Charleux, B. \& Magnet, S. Multistep and semibatch nitroxide-mediated controlled free-radical emulsion polymerization: A significant step toward conceivable industrial processes. J. Polym. Sci., Part A: Polym. Chem 44, 4142-4153 (2006).

26 Maehata, H., Liu, X., Cunningham, M. \& Keoshkerian, B. TEMPO-mediated emulsion Polymerization. Macromol. Rapid Commun. 29, 479-484 (2008).

27 Simms, R. W. \& Cunningham, M. F. Compartmentlization of reverse atom transfer radical polymerization on miniemulsion. Macromolecules 41, 5148-5155 (2008).

28 Dire, C., Magnet, S., Couvreur, L. \& Charleux, B. Nitroxide-mediated controlled/living free-radical surfactant-free emulsion polymerization of methyl methacrylate using a poly(methacrylic acid)-based macroalkoxyamine initiator. Macromolecules 42, 95-103 (2009).
29 Hartmann, J., Urbani, C., Whittaker, M. R. \& Monteiro, M. J. Effect of degassing on surfactant-free emulsion polymerizations of styrene mediated with RAFT. Macromolecules 39, 904-907 (2006).

30 dos-Santos, A. M., Pohn, J., Lansalot, M. \& D'Agosto, F. Combining steric and electrostatic stabilization using hydrophilic macroRAFT agents in an ab initio emulsion polymerization of styrene. Macromol. Rapid Commun. 28, 1325-1332 (2007).

31 Stoffelbach, F., Tibiletti, L., Rieger, J. \& Charleux, B. Surfactant-free, controlled/living radical emulsion polymerization in batch conditions using a low molar mass, surfaceactive reversible addition-fragmentation chain-transfer (RAFT) agent. Macromolecules 41, 7850-7856 (2008).

32 Rieger, J., Osterwinter, G., Bui, C., Stoffelbach, F. \& Charleux, B. Surfactant-free controlled/living radical emulsion (Co)polymerization of n-butyl acrylate and methyl methacrylate via RAFT using amphiphilic poly(ethylene oxide)-based trithiocarbonate chain transfer agents. Macromolecules 42, 5518-5525 (2009).

33 Manguian, M., Save, M. \& Charleux, B. Batch emulsion polymerization of styrene stabilized by a hydrophilic macro-RAFT agent. Macromol. Rapid Commun. 27, 399-404 (2006).

34 Ganeva, D. E., Sprong, E., de-Bruyn, H., Warr, G. G., Such, C. H. \& Hawkett, B. S. Particle formation in ab initio RAFT mediated emulsion polymerization systems. Macromolecules 40, 6181-6189 (2007).

35 Sprong, E., Leswin, J. S. K., Lamb, D. J., Ferguson, C. J., Hawkett, B. S., Pham, B. T. T., Nguyen, D., Such, C. H., Serelis, A. K. \& Gilbert, R. G. Molecular watchmaking: ab initio emulsion polymerization by RAFT-controlled self-assembly. Macromol. Symp. 231, 84-93 (2006).

36 Okubo, M., Sugihara, Y., Kitayama, Y., Kagawa, Y. \& Minami, H. Emulsifier-free, organotellurium-mediated living radical emulsion polymerization of butyl acrylate. Macromolecules 42, 1979-1984 (2009).

37 Kitayama, Y., Chaiyasat, A. \& Okubo, M. Emulsifier-free, organotellurium-mediated living radical emulsion polymerization of styrene. Macromol. Symp. 288, 25-32 (2010).

38 Kitayama, Y., Chaiyasat, A., Minami, H. \& Okubo, M. Emulsifier-free, organotelluriummediated living radical emulsion polymerization of styrene: polymerization loci. Macromolecules 43, 7465-7471 (2010).

39 Kitayama, Y., Moribe, H., Minami, H. \& Okubo, M. Emulsifier-free, organotelluriummediated living radical emulsion polymerization of styrene: initial stage of polymerization. Polymer 52, 2729-2734 (2011).

40 Moribe, H., Kitayama, Y., Suzuki, T. \& Okubo, M. Emulsifier-free, organotelluriummediated living radical emulsion polymerization of styrene: effect of stirring rate. Macromolecules 44, 263-268 (2011).

41 Fitch, R. M., Palmgren, T. H., Aoyagi, T. \& Zuikov, A. Kinetics of partice nucleation and growth in the emulsion polymerization of acrylic-monomers. Angew. Makromol. Chemie. 123, 261-283 (1984).

42 Okubo, M., Kobayashi, H., Matoba, T. \& Oshima, Y. Incorporation of nonionic emulsifiers inside particles in emulsion polymerization: Mechanism and methods of suppression. Langmuir 22, 8727-8731 (2006).

43 Zetterlund, P. B. \& Okubo, M. Compartmentalization in TEMPO-mediated radical polymerization in dispersed systems: Effects of macroinitiator concentration. Macromol. Theory Simul. 16, 221-226 (2007).

44 Kagawa, Y., Zetterlund, P. B., Minami, H. \& Okubo, M. Compartmentalization in atom transfer radical polymerization (ATRP) in dispersed systems. Macromol. Theory Simul. 15, 608-613 (2007).

45 Beuermann, S. \& Buback, M. Rate coefficients of free-radical polymerization deduced from pulsed laser experiments. Prog. Polym. Sci. 27, 191-254 (2002).

46 Zetterlund, P. B., Yamazoe, H., Yamada, B., Hill, D. J. T. \& Pomery, P. J. Highconversion free-radical bulk polymerization of styrene: Termination kinetics studied by electron spin resonance, Fourier transform near-infrared spectroscopy, and gel permeation chromatography. Macromolecules 34, 7686-7691 (2001). 